\title{
Circulação de modelos para o ensino de Ciências Naturais: o método de ensino intuitivo na transição entre Império e República ${ }^{1}$
}

\author{
Patterns in circulation for teaching Natural Sciences: Object Lessons in transition from \\ Empire to Republic
}

Circulación de modelos para la enseñanza de las ciências naturales: el método intuitivo de ensenãnza en la transición entre Imperio y República

\author{
Vera Teresa Valdemarin \\ Universidade Estadual Paulista (Brasil) \\ https://orcid.org/0000-0001-9379-9947 \\ http://lattes.cnpq.br/9701075189282146 \\ vera.valdemarin@unesp.br
}

\section{Resumo}

Este artigo adota a perspectiva histórica (décadas finais do século XIX) para analisar a circulação de prescrições vinculadas ao método de ensino intuitivo. As fontes documentais são dois manuais didáticos dedicados a orientar as práticas pedagógicas de professores primários: Primeiras Lições de Coisas, de N. A. Calkins, publicado em língua portuguesa em 1886 e A Eschola Publica, organizado por Oscar Thompson e outros autores, publicado em 1895. A difusão do método intuitivo ou lições de coisas esteve aliada a transformações pedagógicas que incluem aspectos metodológicos e formação de professores, bem como desenvolvimento social e econômico, tornando-se um símbolo de modernização no estado de São Paulo. Focalizando o ensino de Ciências Naturais, o artigo evidencia diferentes interpretações e sentidos adquiridos pela inovação pedagógica no contexto brasileiro. Essas diferenças explicitam, por sua vez, diferentes concepções sobre a ciência e sobre seu ensino, uma vez que estão assentadas em diferentes formas de raciocínio e hábitos mentais que procuram sedimentar. Um deles, priorizou os passos lógicos para ensinar; o outro foi delimitado às prescrições do currículo escolar.

Palavras-chave: Método de ensino. Lições de Coisas. Ensino de Ciências Naturais. Formação de professores. História da Educação.

\footnotetext{
${ }^{1}$ Este artigo é resultado de pesquisa financiada pelo Conselho Nacional de Desenvolvimento Científico e Tecnológico - CNPq (Processo 311711/2019-7) e pela Fundação de Amparo à Pesquisa do Estado de São Paulo - FAPESP (Processo 2018/26699-4).
} 


\begin{abstract}
This paper takes a historical perspective (final decades of the XIX century) to analyze the circulation of guideline bound to the intuitive teaching method. The documentary sources are two textbooks produced to guide pedagogical practices of elementary teachers: Primary Object Lessons, by N. A. Calkins, published in Portuguese language in 1886, and A Eschola Publica, edited by Oscar Thompson and others, published in 1895. The spread of objective method or object lessons was allied to pedagogical transformations that include methodological aspects and teacher's training. In conjunction with was gathered together wit economic and social development and become a symbol of modernization in São Paulo State. Focusing on Natural Sciences, this article shows different interpretations and meanings taking for pedagogical innovation in the Brazilian context. These differences show, by the way, different conceptions about science and their teaching based on different patterns of reasoning and mental habits. One of them pays particular attention to the step-sequence logic inherent to the teaching method; the other considers the amount of subject prescribed in the school curriculum.
\end{abstract}

Keywords: Teaching methods. Object Lessons. Teaching natural sciences. Teachers training. History of education.

\title{
Resumen
}

Este artículo adopta la perspectiva histórica (décadas finales del siglo XX) para analizar la circulación de prescripciones vinculadas al método de enseñanza intuitivo. Las fuentes documentales son dos libros de texto dedicados a guiar las prácticas pedagógicas de maestros de primaria: Primeiras lições de coisas, de N. A. Calkins publicado en portugués en 1886 y A A Eschola Publica, organizado por Oscar Thompson et al., publicado en 1895. La difusión del método intuitivo o las lecciones de cosas se combino con transformaciones pedagógicas que incluyen aspectos metodológicos y la formación del profesorado, así como el desarrollo social y económico, convirtiéndose en un símbolo de modernización en el Estado de São Paulo. Centrándose en la enseñanza de las Ciencias Naturales, el artículo destaca diferentes interpretaciones y significados adquiridos por la innovación pedagógica en el contexto brasileño. Estas diferencias explican, a su vez, diferentes concepciones sobre la ciencia y su enseñanza, ya que se basan en diferentes formas de razonamiento y hábitos mentales que buscan sedimentar. Uno de ellos priorizó los pasos lógicos para enseñar, el otro se limito a las prescripciones del currículo escolar.

Palabras-clave: Método de enseñanza. Lecciones de cosas. Enseñanza de las ciencias naturales. Formación del profesorado. Historia de la educación. 


\section{Introdução}

A questão dos métodos para ensinar permeia os cursos para formação de professores desde a institucionalização dessa modalidade de instrução no Brasil, que remonta ao século XIX. Na proposição de métodos de ensino - tanto aqueles que, no passado, deixaram suas marcas nos processos de escolarização quanto aqueles que têm como objetivo alterar esses mesmos processos no presente e no futuro - estão articulados valores, finalidades e concepções pedagógicas que, traduzidas em procedimentos e atividades, aspiram não apenas a referendar princípios mas também a estabelecer continuidades práticas ${ }^{2} \mathrm{e} u m$ repertório de conhecimentos a ser operacionalizado e repetido. As diretrizes sobre "como ensinar" não se limitam aos procedimentos técnicos, mas carreiam implicações para o conteúdo a ser ensinado e para as organizações curriculares de diferentes níveis de escolarização e, em geral, instauram conflitos nas diversas instâncias envolvidas em sua proposição e execução. Esse processo é dinâmico, é constituído na complexa combinação de práticas inovadoras e outras já sedimentadas e é produzido tanto por teóricos de diferentes áreas do conhecimento quanto por professores em sala de aula, além de mobilizar grande variedade de meios e materiais para sua difusão.

Neste artigo, adota-se a perspectiva histórica para examinar essa questão e, para tanto, são analisadas fontes documentais elaboradas como prescrições para a prática de ensino vinculadas à renovação metodológica desencadeada no Brasil nas décadas finais do Império e que se estendeu aos anos iniciais do regime republicano. Delimitada aos conteúdos relativos ao ensino das Ciências Naturais no curso primário, essa análise pretende compreender a dinâmica da circulação de inovações metodológicas identificando os múltiplos vetores entrecruzados nas orientações consignadas aos mesmos fundamentos, notadamente, os agentes e instituições envolvidos no processo e os dispositivos mobilizados para sua disseminação. Entende-se que na interação desses elementos é possível captar os sentidos conferidos à inovação pedagógica e à cultura científica do período.

As fontes documentais utilizadas são dois livros dirigidos aos professores da escola primária, concebidos para veicular prescrições metodológicas referentes ao método de ensino intuitivo. Trata-se do manual didático Primeiras Lições de Coisas, de autoria do norteamericano Norman Allison Calkins, publicado em 1886 e do livro A Eschola Publica - Ensaio de Pedagogia Prática, publicado em 1895, como resultado da compilação dos onze números da revista A Eschola Publica que haviam circulado nos anos de 1893 e $1894 .^{3}$

Embora diferentes em termos de autoria e de processos de editoração, os impressos selecionados têm em comum a veiculação de conteúdo a ser ensinado, a apresentação de modelos de aula e de instruções aos professores, alegadamente crivados pela experiência profissional de seus autores, além de afirmarem explicitamente o vínculo aos fundamentos pestalozzianos e aos processos intuitivos para a aprendizagem. As duas fontes documentais dedicaram-se à difusão do método de ensino que, articulado a reformas pedagógicas, era considerado recurso eficiente para provocar repercussões positivas não apenas na escola, mas também na sociedade em geral. No contexto brasileiro, ele adquiriu a conotação de modernização pedagógica e, no estado de São Paulo, se tornou símbolo das políticas

\footnotetext{
${ }^{2}$ A expressão “continuidades práticas” é utilizada por Raymond Williams (1979) para descrever, no processo de incorporação cultural, os elementos diretamente experimentados que atuam na elaboração de significados e abrangem tanto as concepções doutrinárias como o modo de praticá-las e, em geral, são manejados em instituições e outros espaços formadores.

${ }^{3}$ O periódico A Eschola Publica foi publicado entre 1893 e 1897 com interrupções e tiragem de 1.000 exemplares em cada edição mensal. Seus organizadores e analistas apontaram, adequadamente, a existência de duas fases distintas na circulação do periódico, que podem ser identificadas em alterações gráficas, mudanças do grupo de editores, incremento do número de colaboradores e de seções e, consequentemente, de conteúdo. A primeira fase teve onze volumes publicados entre 1893 e 1894 e a segunda, 10 volumes que vieram a público entre 1896 e 1897.
} 
educacionais aliadas ao regime republicano, após sua implantação (SOUZA, 1998; CARVALHO, 2000; MONARCHA, 1999).

A defesa desse método específico para elevar os patamares educacionais brasileiros foi encampada por monarquistas e republicanos na transição entre esses dois regimes de governo. Em 1879, ele adquiriu caráter legal com a promulgação do Decreto $n^{0} 7.247$, de 19 de abril (BRASIL, 1942), que regulamentava o ensino primário e secundário no município da Corte, e permaneceu nas orientações oficiais do estado de São Paulo até 1920. Este Decreto foi publicado por ordem do ministro de Estado dos Negócios do Império, Carlos Leôncio de Carvalho, que participava ativamente de iniciativas educacionais que, sob diferentes auspícios, surgiram na província de São Paulo. No entanto, mais contundente do que a prescrição na legislação, foi a defesa do método feita pelo então deputado Rui Barbosa por meio de um alentado parecer ao Decreto e da tradução do manual didático Primeiras Lições de Coisas, de N. A. Calkins. O parecer publicado em 1883 com a denominação de Reforma do ensino primário e várias instituições complementares da instrução pública (BARBOSA, 1947) aliado à tradução constituem prolífico conjunto de documentos nos quais estão descritos tanto os problemas educacionais brasileiros como a esperança de revertê-los com a introdução de novas práticas num sistema escolar a ser também renovado.

O livro Ensaio de Pedagogia Prática é resultado da compilação de onze volumes do periódico A Eschola Publica, considerado uma das primeiras e bem sucedidas iniciativas da imprensa pedagógica paulista (CATANI, 2003). ${ }^{4}$ Esses impressos são contemporâneos à reforma educacional liderada por Gabriel Prestes e promulgada em 1892, que estruturou o ensino no estado de São Paulo após a proclamação da República. Nessa estrutura, a Escola Normal e as Escolas-Modelo eram pensadas como polos irradiadores de demonstração metodológica e, atuando nessas instituições, os editores d'A Eschola Publica transcreviam no periódico as aulas lá ministradas e alguns exercícios de alunos para divulgar aos leitores os procedimentos adotados e os resultados obtidos, a fim de elucidar "a quem quer que frequentar não possa, quaes os processos usados na Eschola Modelo" (MOTTA, 1894, apud THOMPSON et al., 1895, p. 8), principalmente, aqueles intuitivos derivados das proposições de Pestalozzi.

Entende-se que colocar a questão dos métodos para ensinar no centro da análise, como se faz aqui, permite demonstrar que a partir desse elemento didático, podem ser detectadas interações entre atores, dispositivos, discursos e práticas que modularam os sentidos adquiridos pela inovação pedagógica. Para tanto, procura-se caracterizar interpretações, criações e prescrições destinadas a balizar os modos de uso do método intuitivo, focalizando mais detidamente o ensino relativo às Ciências Naturais.

\section{A versão modelar do método de ensino intuitivo}

É inequívoca a intenção de Rui Barbosa de oferecer aos legisladores brasileiros, no final do período monárquico, um projeto educacional modelar por meio da elaboração do conjunto de Pareceres sobre o ensino e da tradução do manual didático de N. A. Calkins. A bibliografia estrangeira consultada, os dados estatísticos mobilizados, as tentativas de obter financiamento para a publicação do livro e o projeto de lei decorrente desse estudo materializam eloquentemente seu propósito de estruturar o sistema em todos os níveis e divulgar um conjunto de práticas pedagógicas destinadas a balizar a formação dos professores, eixo central das mudanças pretendidas.

\footnotetext{
${ }^{4}$ Esse periódico tem sido utilizado como fonte para estudos em diferentes perspectivas. Entre elas, pode-se indicar o de Marta Carvalho (2001), que sintetiza suas possibilidades pedagógicas na expressão "caixa de utensílios"; o de Adriana Pinto (2012), que o caracteriza editorialmente, o de Marcus Aldenison de Oliveira (2018), que focaliza as lições relativas ao ensino de Aritmética e o de Valdemarin e Pinto (2010) que trata dos fundamentos do método de ensino intuitivo.
} 
Para legitimar a escolha do manual de Calkins, o tradutor elabora um elogioso preâmbulo e, nele, destaca as qualidades da obra comparando-a a outras do mesmo gênero e reproduz a avaliação exarada por Ferdinand Buisson, representante do governo francês na Exposição Internacional da Filadélfia, realizada em 1876: "a melhor coleção de lições de coisas, até então publicada" (CALKINS, [1886], 1950, p. XVI). Com esse respaldo, indica aos leitores que, apesar das diferenças entre os continentes europeu e americano, ambos adotavam o mesmo caminho para o progresso: a reforma do ensino e a utilização do método intuitivo. Para ele, o maior mérito da obra estaria na descrição dos processos destinados a exercitar os sentidos e a inteligência por meio da observação, o que resultaria em melhor formação dos estudantes que, por sua vez, contribuiriam para elevar os patamares sócio-educacionais brasileiros. Além disso, inclui uma profusão de notas explicativas e capítulos de sua própria autoria para adequar o conteúdo a seus potenciais leitores 5 .

Outra estratégia legitimadora da tradução assenta-se na incorporação à edição brasileira de prefácios do próprio autor. Por meio deles, informa-se que a primeira edição das Primeiras Lições de Coisas foi publicada em 1861, nos Estados Unidos da América, com o objetivo de sistematizar as ideias de Johann Heinrich Pestalozzi (1746-1827) em procedimentos didáticos. N. A. Calkins afirma que o conteúdo do manual, baseado em sua experiência profissional, é detalhado e circunstanciado para atender às necessidades dos professores e, por isso, contém a descrição de cada um dos passos necessários para ensinar e desenvolver o espírito da criança, acompanhados de exemplos e demonstrações. O potencial educativo do método de ensino é reafirmado no prólogo da $15^{\text {a }}$ edição (1870): o autor esclarece que pretendeu "demonstrar praticamente ainda com mais clareza, os princípios do verdadeiro ensino objetivo e as relações deste método de ensinar para com os ramos ordinários da instrução na escola" (CALKINS, 1950, p. 23, grifos no original). Informa também que as supressões e os acréscimos de exemplos foram ditados pela prática e dizem respeito à exposição do assunto e não aos princípios, que são "verdadeiras leis, deduzidas da natureza dos espíritos que se têm de instruir" (CALKINS, 1950, p. 24, grifos no original) e, por isso, são imutáveis; já a apresentação dos objetos de ensino aos alunos pode variar, como tem sido demonstrado nas sucessivas edições. No proêmio da $40^{a}$ edição (1884), o autor afirma que permanece inabalada sua crença nas qualidades do ensino objetivo e que foram acrescentadas sugestões, conselhos aos professores e diretrizes para o ensino de Leitura e Desenho ${ }^{6}$.

A organização do manual norte-americano não foi alterada na tradução brasileira e, explicitando os fundamentos empiristas do método de ensino (VALDEMARIN, 2004, 2006) a ser descrito, a ordem dos capítulos denota a importância atribuída a cada um dos sentidos humanos - os canais da percepção e das ideias - no processo de aprendizagem. ${ }^{7}$ A visão é considerada o sentido mais atuante e, por isso, o manual tem início pelo ensino das Formas, conteúdo propício, segundo o autor, para descrever detalhadamente os passos do método e para exercitar professores e estudantes no seu emprego em sala de aula. Na sequência, são apresentadas as lições sobre a Cor, sobre o Número e as quatro operações, sobre o Tamanho, sobre o Desenho e sobre o Tempo, conteúdos que envolvem diretamente a observação de

\footnotetext{
${ }^{5} \mathrm{O}$ tradutor faz uso extensivo das notas de rodapé para explicar determinadas escolhas linguísticas, os acréscimos para, a seu ver, elucidar o texto original e justificativas para a criação de, pelo menos, três lições: sobre os sons e sobre o ensino da leitura, cujo conteúdo original não era compatível com o ensino da língua portuguesa e acrescenta uma lição sobre o ímã, da qual tomou conhecimento no já mencionado parecer de Ferdinand Buisson.

${ }^{6}$ Informações sobre a trajetória profissional de N. A. Calkins são fornecidas por Lourenço Filho no Prefácio do volume XIII das Obras Completas de Rui Barbosa (1950): iniciou a carreira como professor e diretor de escolas primárias no interior no estado e na cidade de Nova York; o prestígio angariado com a publicação do manual alçou o autor ao posto de diretor das escolas primárias de Nova York e de presidente da Associação Nacional de Educação, cargo que ocupou por cerca de trinta anos.

${ }^{7}$ Vale indicar que Calkins é co-autor de um manual destinado aos professores que segue a organização curricular da escola primária na exposição das lições e conteúdos. Ver: KIDDLE; HARRISON; CALKINS, 1873.
} 
objetos. Para educar a audição e garantir que este sentido atue no desenvolvimento da inteligência, são apresentadas as lições sobre o Som e sobre a Leitura Elementar, que se assenta nos sons da linguagem. As lições sobre as Qualidade das Coisas, preparam para o ensino das Lições de Coisas, propriamente ditas, e para as lições sobre o Corpo Humano que, sendo mais complexas devido à confluência de diferentes sentidos, englobam as habilidades para discriminar, classificar e associar as ideias provenientes dos objetos e dos fenômenos naturais $\mathrm{e}$, consequentemente, impulsionam o desenvolvimento dos processos mentais em geral.

Autor e tradutor, portanto, afiançam que o objetivo do manual é contribuir para a formação dos professores - iniciantes ou em exercício - por meio da descrição da sequência adequada para ensinar e desenvolver o espírito das crianças e, para isso, são apresentados modelos de lições para exemplificar, segundo eles, de modo claro e circunstanciado, os passos a serem adotados na execução do método e, consequentemente, o desdobramento dos princípios em práticas.

Os princípios invariáveis nos quais são radicadas todas as lições podem ser assim sintetizados: o conhecimento é derivado do contato dos sentidos com os objetos e fenômenos do mundo exterior, sendo a percepção o primeiro estágio do desenvolvimento da inteligência, por isso, a educação deve cultivar os canais perceptivos oferecendo oportunidades e estímulos para que eles sejam exercitados. A primeira operação da percepção consiste na identificação de semelhanças e diferenças entre os objetos e, progressivamente, evolui para a associação e para a classificação. Uma vez que o desenvolvimento das faculdades perceptivas depende da adequação dos exercícios que lhe são oferecidos, estes devem incentivar a atenção, a curiosidade e a autonomia das crianças.

Nas palavras do autor, o processo para ensinar progride "do simples para o complexo; do que se sabe, para o que se ignora; dos fatos, para as causas; das coisas, para os nomes; das ideias, para as palavras; dos princípios, para as regras" (CALKINS, 1950, p. 31) porque o processo para aprender tem início com a percepção proveniente das sensações e "a atenção, fixada no que se percebeu, leva à observação. Enfim, graças à observação, à comparação e classificação das experiências e dos fatos, alcançamos o conhecimento" (CALKINS, 1950, p. 31, grifos no original).

Nesta concepção, o ensino primário deveria cultivar os "hábitos de observação acurada", a fim de que o conhecimento sobre as coisas precedesse o conhecimento das palavras que, por sua vez, devem expressar ideias realmente adquiridas e não apenas sons vazios de significado. É de se notar, portanto, que para a prática desse método, os livros são materiais secundários pois, feitos de palavras, são úteis apenas quando expressam ideias provenientes das coisas. Para melhor esclarecer esse processo, o autor afirma que só a observação e a experiência podem transformar as palavras em "pinturas dessa realidade significada nos caracteres impressos” (CALKINS, 1950, p. 34).

Para implementar esses princípios, a instrução deve ser sustentada, pelo menos durante os dois primeiros anos de escolarização, por diálogos sobre os interesses, as coisas e os fatos conhecidos pelas crianças, com a finalidade de desenvolver a observação e a linguagem, de acordo com a seguinte orientação:

Convém que as primeiras lições da criança na escola sejam dadas em conversas e com a maior simplicidade, para despertar o espírito, desenvolver os hábitos de observação, e adestrar os alunos no emprego da linguagem. Esse trabalho prepara-los-á para um estudo mais preciso das formas, cores, números e palavras impressas (CALKINS, 1950, p. 59)

Esses diálogos são constituídos por perguntas cujas respostas não sejam meramente sim ou não (o que vejo? o que ouço? o que saboreio? o que cheiro? o que apalpo? o que faço? aonde vou? Como vou?, etc.), mas descrevam o que foi observado e versem sobre objetos de uso comum, tais como, brinquedos, vestuário, mobília da casa e da escola, entre outros. 
A Forma, segundo o autor, é o conteúdo ideal para iniciação no método porque é uma propriedade variável, facilmente percebida pela visão, presta-se a ser descrita com palavras simples e possibilita exercitar a observação, a comparação e a classificação. A sequência de passos constitutiva do método, fartamente exemplificada no ensino da Forma, é a mesma para todos os conteúdos: colóquios sobre objetos conhecidos, dos quais são observadas e nomeadas as características aparentes, as quais constituem a base para a comparação com outros objetos de modo a estabelecer semelhanças, diferenças, usos e material de que são feitos. A etapa final do método consiste em retornar aos objetos familiares com exercícios práticos para recapitular e verificar a progressão no conhecimento. A colher, por exemplo, é objeto bastante presente nas atividades cotidianas das crianças e, por isso, pode ser tomada como objeto didático a fim de entabular diálogos na sala de aula; ao final do processo, deve ser descrita como um objeto de "forma oval, côncava, cabo estreito, achatado, que se alonga para a parte oposta à concha" (CALKINS, 1950, 174) e que apresenta variações de tamanho, usos e materiais.

$\mathrm{O}$ autor esclarece que não se trata, apenas, de usar objetos triviais, mas de usa-los obedecendo tendo em vista o desenvolvimento dos alunos. Na primeira fase da aprendizagem os objetos deverão ser distinguidos pelo nome, ter identificadas suas partes principais, a forma, a cor e usos. A observação deve incidir sobre objetos já conhecidos, tais como, bolas de bilhar, cadeiras, sinos, alfinetes, chapéus, sapatos e portas. Na segunda fase, devem ser distinguidas forma, cor, tamanho, matéria, qualidades, aplicações e origens e são tematizados os elementos naturais transformados pelo homem e entre eles, o manual contém lições sobre a esponja, a água, o leite, o vidro, o açúcar, a cortiça e a madeira. Essas lições são destinadas ao aprimoramento da observação e consistem em exercícios para agrupar e distinguir qualidades, devendo resultar na aprendizagem das diferenças entre áspero e liso, frágil e resistente, opaco e transparente, etc.. Na terceira fase das Lições de coisas, reitera-se que o estudo deve ser aprofundado, principalmente quanto ao uso que se faz dos objetos e quanto à observação das propriedades pelas próprias crianças e, para isso, “o mestre há de encaminhá-las a notar as qualidades, mas não lhes diga as que os alunos puderem prontamente descobrir" (CALKINS, 1950, p. 505). Nesta fase, o manual traz apenas planos gerais das lições e sugestão de objetos a serem tratados, "deixando ao mestre a seleção dos exercícios, experiências, colóquios e perguntas aos discípulos acerca das coisas, suas propriedades, aplicações, etc.” (CALKINS, 1950 , p. 505), pressupondo que, assim como os alunos, os professores tenham adquirido autonomia no uso do método.

O conteúdo largamente denominado como Ciências Naturais não está assim discriminado no manual de Calkins, mas os temas a ele referentes podem ser identificados em diferentes lições, o que torna possível analisa-lo de modo particularizado. ${ }^{8}$

O estudo sobre a água exemplifica as várias entradas que um mesmo tema comporta na descrição metodológica do manual. As lições sobre as qualidades são destinadas a identificalas e, simultaneamente, agrupar os elementos que as possuem. Nesse contexto didático, a água é o elemento observado para descrever a transparência, qualidade das "coisas através das quais facilmente se vê" (CALKINS, 1950, p. 450) e é distinguida, pelo mesmo processo, daquelas que não têm essa propriedade (as opacas). Ela também está presente na lição dedicada a observar a liquidez, a fluidez e a propriedade que certos líquidos têm de gotejar, umedecer ou molhar, bem como na lição dedicada à observação da solubilidade de alguns elementos.

\footnotetext{
${ }^{8} \mathrm{~A}$ denominação das matérias no manual não é idêntica àquela adotada na escola primária brasileira do período, dado o critério, já explicitado, para a organização do manual. No entanto, há conteúdos comuns aos dois registros, com ênfases diferenciadas. As lições sobre a Forma, por exemplo, correspondem ao conteúdo que aqui aparecia sob as rubricas de Desenho, Geometria e Formas; as extensas lições sobre as cores apareciam no currículo como temas do programa de Física e Química.
} 
O autor adverte que esses exercícios não devem ser convertidos em memorização de definições, mas devem contribuir para o estabelecimento do hábito de observação para, assim, influenciar "nos métodos gerais de ensino professados na escola (CALKINS, 1950, p. 463).

Se nas lições sobre as qualidades, a água é utilizada para agrupa-las de acordo com o sentido que as percebe, na segunda fase das Lições de Coisas (que, em geral, coincide com o segundo ano do curso primário), seu estudo, propriamente dito, é iniciado com conversas entre professor e alunos sobre seus usos e aplicações (beber, comer, lavar) e prossegue com indicações para "observarem e exprimirem o aspecto que ela tem" (clara, transparente, incolor, inodora, líquida) e suas propriedades: "que goteja, e umedece, de onde se segue que pode ser líquida" (CALKINS, 1950, p. 496, grifos no original). Assim, qualidades abordadas em lições anteriores são retomadas para caracterizar e particularizar um elemento; a elas são acrescentadas novas observações, tais como sua proveniência em dias de chuva ou explicações sobre arroios, fontes, regatos e nascentes, estendendo-se os raciocínios para a formação de rios. Outras propriedades são, pouco a pouco, introduzidas: "Advirtam igualmente em que, sob a influência do calor, a água se faz vapor, ou evapora, assim como sob a ação do frio endurece, tornando-se em gelo ou congelando-se" (CALKINS, 1950, p. 496, grifos no original), o que amplia seus usos em cada um desses estados (aquecimento, preservação).

O estudo sobre a água é finalizado com a elaboração de um quadro, descrito abaixo, composto por três colunas nas quais estão listadas as qualidades, os usos e locais de sua obtenção, com a orientação para seja utilizado como roteiro para a produção de textos.

\section{ÁGUA}

$\begin{array}{lll}\text { Qualidades } & \text { Usos } & \text { De onde se obtém } \\ \text { Transparente } & \text { Beber } & \text { Das nuvens. } \\ \text { Insípida } & \text { Cozer } & \text { Na chuva } \\ \text { Incolor } & \text { Lavar } & \text { Do chão } \\ \text { Inodora } & \text { Mover máquinas } & \text { Por meio de fontes e poços } \\ \text { Líquida } & \text { Aquecer casas } & \text { De regatos e rios } \\ \text { Evaporável } & \text { Preservar víveres } & \text { De tanques e lagos }\end{array}$

(CALKINS, 1950, p. 497).

Um capítulo do manual, o penúltimo, é dedicado, exclusivamente, ao corpo humano. $\mathrm{O}$ estudo deste tema das Ciências Naturais constitui, segundo o autor, a base para o estudo posterior da Fisiologia. Seu ensino assenta-se na analogia entre casas e corpos: "as casas como lugares de habitação; o corpo como a casa ou mansão da alma” (CALKINS, 1950, p.521).

Observando-se um boneco, é possível nomear as partes que, em conjunto, compõem seu corpo e identifica-las no corpo das crianças: "a cabeça, o pescoço, o tronco, os braços, as mãos, as pernas e os pés" (CALKINS, 1950, p. 522). A seguir, vêm as lições sobre os movimentos observáveis da respiração e sua função na manutenção da vida, que levam, por similaridade, à explicação sobre a circulação sanguínea e sobre a função dos alimentos e do coração.

No estudo do rosto e de suas partes constitutivas que, por sua vez, integram a cabeça, os diálogos entre professor e alunos devem levar à observação das características mais aparentes, isto é, sua forma "redonda, ou oval, estreitando para baixo [...]; o nariz ao meio do rosto, alongado na direção de cima a baixo, piramidal [...]" (CALKINS, 1950, p. 526). Na dinâmica das prescrições metodológicas, os conhecimentos anteriores sobre as formas são aplicados ao corpo humano e a eles são acrescentadas novas especificidades, tais como "a 
propriedade, que tem a fisionomia, de revelar tantas coisas a nosso respeito", os sentimentos de alegria e tristeza e "a boa ou maligna disposição de nossa índole" (CALKINS, 1950, p. 526).

As lições acerca dos órgãos dos sentidos são oportunidade para retomar a analogia do corpo com as casas e exaltar sua função na aquisição do conhecimento: "o ouvido, como a porta por onde têm ingresso os sons; os olhos, como as janelas por onde a alma olha para fora, e desfruta a formosura das maravilhas do universo; as pálpebras, como as cortinas dessas janelas" (CALKINS, 1950, p. 535, grifos no original). Essas lições, portanto, funcionam como a justificativa biológica para o método de ensino exposto no manual.

Os exercícios destinados a agrupar semelhanças e diferenças possibilitam que o professor converse sobre a pele que reveste os animais como, por exemplo, o carneiro, a vaca, o cavalo, o gato, o cão e a plumagem das aves, até chegar à pele que reveste o corpo humano. Dela, devem ser observadas a elasticidade (repuxando a pele e deixando-a voltar à posição natural) e a flexibilidade (dobrando-se os dedos). Pode-se também usar horas de intenso calor para ensinar que

a transpiração ou suor, nos permeia a pele, atravessando uns orificiozinhos, que têm o nome de poros. Inquira a designação, que damos aos corpos crivados desses pequeninos orifícios. Diga-lhes que chamamos porosa a pele, por ser crivada de uns furos miudíssimos, por onde coa o suor. Tão sutis e numerosos são esses poros, que a ponta do dedo mínimo, apoiada na mão, ou no rosto, cobre milhares deles (CALKINS, 1950, p. 549, grifos no original).

Vale destacar que a porosidade já foi observada como qualidade de diferentes materiais em outras lições e que os exemplos sobre cada característica podem ser estendidos conforme a necessidade, desde que, ao final de cada etapa seja redigido o sumário do que foi aprendido.

Assim, a análise dessa fonte permite afirmar que o método de ensino intuitivo na versão de N. A. Calkins foi introduzido no Brasil como parte de um conjunto mais amplo de medidas voltadas para a reforma da educação. Produzidas no período monárquico, as propostas de Rui Barbosa - aí incluídas as prescrições do manual traduzido - descreviam um aparato educacional a ser ainda criado e, nele, o método de ensino desempenhava função estratégica, o que justificaria a escolha de uma versão detalhadamente descrita e os diferentes marcadores intersectados com os quais pretendeu atribuir-lhe distinção: tradução, recomendações e adequações referentes à língua portuguesa. Nesse conjunto, o método proposto por Calkins destinava-se a apresentar aos professores e às instituições formadoras, as prescrições bem como suas justificativas teóricas, para a introdução de novas práticas docentes. Utilizando a expressão de Sobe (2013), pode-se dizer que autor, tradutor e a obra exerceram a função de credenciamento do método de ensino intuitivo no Brasil e, juntos, conferiram-lhe o sentido da inovação.

\section{A pedagogia prática na versão do manual $A$ Eschola Publica}

Outras prescrições para a utilização do método de ensino intuitivo na escola primária entrecruzavam-se nos anos finais do Império e iniciais da República, apesar do esforço de Rui Barbosa para distinguir as características daquelas produzidas por N. A. Calkins. No município da Corte e na província de São Paulo diferentes iniciativas, principalmente particulares, visavam introduzir mudanças nos métodos e materiais de ensino, nos processos de alfabetização e na formação de professores, tanto por meio de cursos regulares, como de conferências e palestras (ver HILSDORF, 1986; MORAES, 1998; RIO DE JANEIRO, 1884; BASTOS, 2002; SCHELBAUER, 1998).

Após a instauração do regime republicano, o grupo que assumiu o poder no estado de São Paulo, implementou política assentada na difusão da instrução e na melhoria de sua 
qualidade. A reforma educacional de 1892, iniciada por Caetano de Campos e continuada por Gabriel Prestes, fez do curso para formação de professores da Escola Normal da capital e das Escolas-Modelo Anexas os centros das inovações nas práticas de ensino. Reis Filho (1981), apoiado em relato de estudante, afirma que a formação pedagógica dos futuros professores tinha início com a observação das aulas dadas na Escola Modelo, a fim de "incorporar pela visualização os mecanismos do procedimento de aula. Com duas horas diárias de observação deverá preparar-se para reproduzir, quando chegar sua vez" (REIS FILHO, 1981, p. 73) os procedimentos e o material utilizado. Para viabilizar essa estratégia foram contratadas duas professoras com experiência e formação nos processos de ensino norte-americanos, mesma rota adotada por Rui Barbosa para a difusão do método. ${ }^{9}$

A criação da revista A Eschola Publica é parte desse esforço reformador pois, atuando nas instituições recentemente estruturadas, seus editores transcreviam no periódico as aulas lá ministradas e alguns exercícios de alunos, fazendo dessa condição profissional e institucional a avalista das prescrições veiculadas. Carlos da Silveira, um dos primeiros analistas dessa revista explica sua criação a partir da conjunção de vários fatores: "mestres novos, métodos recentemente introduzidos, processos ainda não muito vulgarizados" (SILVEIRA, 1929, p. 323) que, juntos justificavam o investimento num impresso que ecoasse as mudanças junto aos leitores.

A primeira fase do periódico é composta por 11 números publicados entre 1893 e 1894 e teve como editores e principais autores os professores Oscar Thompson, Antonio Rodrigues Alves Pereira, Joaquim de Sant'Anna, e Benedicto Maria Tolosa e, em 1895, com algumas supressões e acréscimos, o conteúdo dessas edições foi compilado em um livro, aqui analisado, que, mantendo o mesmo título da revista, recebeu subtítulo para explicitar claramente suas pretensões - Ensaio de Pedagogia Prática - e identificar a iniciativa: Pedagogia paulista.

Os organizadores afirmam que a publicação não era vinculada a nenhum órgão oficial e, para mantê-la estimulavam assinaturas, cobravam pagamentos em atraso e ofereciam brindes: carta com os principais aforismos de Pestalozzi, em impressão de luxo que "pode ser pregada na parede das salas de aula ou de professores" (A ESCHOLA PUBLICA, 1894, n 6, p. 48). Do ponto de vista ideológico, no entanto, a revista alinhava-se inteiramente aos propósitos de fazer da instrução um dos pilares de sustentação do regime republicano (cf. em CARVALHO, 2003). Os quatro editores eram egressos da Escola Normal da capital e, em início de carreira, atuavam no magistério ou na direção de escolas (SILVEIRA, 1929). Oscar Thompson teve trajetória mais longa e ocupou os postos mais altos do sistema educacional paulista e, antes disso, foi professor e diretor da Escola Modelo do Carmo e diretor interino da Escola Normal da capital (MONARCHA, 1999; GONCALVES, WARDE, 2002); Antonio R. Alves Pereira e Benedicto Maria Tolosa, eram professores da Escola-Modelo situada na Praça da República e participaram, posteriormente, de outros projetos editoriais e discussões sobre métodos de ensino de leitura, inclusive com publicação de livros (MORTATTI, 2000).

Diferentemente do manual de Calkins, a exposição dos conteúdos no livro A Eschola Publica estava vinculada às finalidades do ensino primário - ler, escrever e contar - e denotava suas hierarquias: Leitura, Aritmética e Linguagem tinham precedência sobre as outras matérias; no entanto, maior número de páginas era ocupado pelos conteúdos referentes às Ciências da Natureza subdivididas em Zoologia, Botânica, Física, Química e Biologia. Publicadas nas sucessivas edições do periódico, as lições forneciam uma percepção fragmentada do que deveria ser ensinado, já a organização por matérias adotada no livro revelava o desenho curricular em vigor. Esse agrupamento também conferia destaque à autoria das lições: Oscar Thompson escreveu as lições sobre Aritmética; A. Pereira foi o responsável pelas lições de Leitura Intuitiva, Botânica e Zoologia;

\footnotetext{
${ }^{9}$ Trata-se de Maria Guilhermina Loureiro de Andrade e Miss Marcia Browne. A primeira, carioca, havia estudado nos Estados Unidos e a segunda, norte-americana, ex-diretora de Escola Normal, encontrava-se atuando em São Paulo (CHAMON, 2005; REIS FILHO, 1981).
} 
Benedicto Tolosa expôs as lições de Linguagem e Desenho e Joaquim Sant'Ana apresentou aquelas de Física, Química, Cosmografia e de alguns aspectos de Zoologia.

De acordo com seus organizadores, o livro e o periódico A Eschola Publica pretendiam focalizar os aspectos práticos da docência, o que pode justificar a inexistência da exposição dos fundamentos sobre os quais se assentavam os modelos de aula. Era clara, no entanto, a filiação aos princípios pestallozianos (reproduzidos ao final do livro e em epígrafes) mas, na interpretação paulista, a inovação metodológica foi conformada, como se verá, sob parâmetros diferentes daqueles expostos por Calkins.

A diferença menos sutil pode ser constatada com relação a um dos conteúdos centrais na exposição do método em sua versão norte-americana. No ano de 1894 foram publicadas na revista vinte lições nomeadas como Linguagem em Lições de Coisas, sem autoria determinada, informandose que com elas, obteve-se bons resultados na Escola Modelo. Trata-se mais de esquemas do que de modelos de aulas, acompanhados da orientação de que podem ocupar cerca de 15 minutos diários e que fornecem "assunto para muitos dias". O excerto abaixo ilustra a mencionada diferença:

Lição I - Nomes dos objetos

Objeto. Objetos designados pelos seus nomes.

Método. Ponha nas mãos das crianças objetos comuns. Faça cada criança dizer o que ela ou outra qualquer criança tem.

Resultado. Serão expressões orais como esta: Eu tenho uma bola. João tem um livro. A Sara tem uma campainha. (A ESCHOLA PUBLICA, 1894, p. 45).

Como se pode verificar, não há indicações nem detalhamento dos passos a serem obedecidos para que a percepção dos sentidos se torne uma ideia, mas a formação de frases indica claramente que o objetivo central do esquema diz respeito ao ensino da Linguagem.

Esse conjunto de lições, no entanto, foi excluído do livro publicado em 1895, o que constitui indicativo do sentido que estava sendo conferido ao método, o que pode ser acompanhado também na análise das disciplinas voltadas para o ensino das Ciências Naturais.

Os conteúdos designados como Zoologia em lições de coisas e Classificação dos animais, assinados por A. Pereira, têm início com o estudo do corpo humano. O autor orienta que a discriminação das partes do corpo deve se dar "sempre fazendo a criança apontar para a parte do corpo que nomeia" (PEREIRA, 1895, p. 96). De acordo com o modelo de aula apresentado, o diálogo deve conduzir as crianças a apalparem os próprios rostos, mãos e braços a fim de perceberem a diferença de texturas, as quais o professor nomeia: ossos, carne e pele. O mesmo procedimento leva a discriminar cabeça, tronco e membros e suas sub partes e com as respostas dos alunos será organizada a lição, como se pode conferir no excerto abaixo:

O professor deve chamar a atenção dos alunos para a forma da cabeça, lembrando-lhes a figura geométrica aproximada dessa parte do corpo, ensinando-lhes a formação das palavras esférica, esferoidal; assim como em relação ao pescoço ensinará que ele se parece com um cilindro e que por isso tem a forma cilíndrica (PEREIRA, 1895, p. 97).

As lições devem prosseguir com a observação das diferentes partes do corpo humano, que são nomeadas e descritas em termos de suas características. $O$ autor orienta que as perguntas devem ser feitas até que seja possível chegar aos seguintes termos: "O corpo humano se divide em cabeça, tronco, membros. Os membros de cima chamam-se membros superiores e os membros de baixo, membros inferiores" (PEREIRA, 1895, p. 96, grifos no original). Há recomendações para que, sempre que for oportuno, sejam introduzidos conselhos sobre 
alimentação, higiene e posturas corporais. Como esse conteúdo ocupa grande parte do programa escolar, A. Pereira orienta para evitar as noções abstratas com as crianças menores e priorizar aquelas provenientes das percepções dos sentidos.

Respeitando a mesma progressão adotada no ensino do corpo humano, deve ser ensinada a classificação dos animais, que tem início com aqueles mais conhecidos, os domésticos - o cão, o gato, o cavalo, o boi - dos quais as crianças enunciam as raças conhecidas antes de observarem um cãozinho trazido à sala, por exemplo. Quando não for possível observar o próprio animal, pode-se lançar mão das gravuras e, ao sumariar a utilidade dos cães para a proteção, o autor dá a seguinte orientação: "convém o professor ilustrar esta sentença explicando o que são ovelhas e dando uma noção do que sejam animais ferozes" (PEREIRA, 1895, p. 103) ou "deve o professor ilustrar com histórias verossímeis" (PEREIRA, 1895, p. 105) quando mencionar que os cães podem proteger os homens.

Para que se estabeleça entre os alunos a ideia do que é um animal doméstico, recomenda-se diálogos que levem ao seguinte resultado:

Os animais domésticos são os que vivem com o homem, acompanhando-o em seus trabalhos e prestando-lhes serviços.

Há animais domésticos cuja utilidade consiste em nos alimentar com sua carne.

O cão, o gato, o carneiro, o boi, a galinha, o ganso, o cavalo, o burro, o cabrito são animais domésticos (PEREIRA, 1895, p. 102).

O autor ressalva que nas lições para os anos iniciais do curso preliminar apresentou "uma classificação de fácil assimilação e não de inteira justeza científica" e, seguindo as indicações contidas nos programas escolares, acrescentou no livro lições sobre os animais selvagens e sobre os anelados e moluscos.

A. Pereira também assina as lições de Botânica, as quais versam sobre flor e folhas, com a orientação para que, sempre que possível, deve-se "fazer o estudo nas próprias plantas; assim é de muita vantagem que os meninos estudando, por exemplo, a flor, tenham uma para observá-la" (PEREIRA, 1895, p. 273). Para o estudo do caule podem ser utilizados vasos de plantas ou informações obtidas em passeios pelos arredores da escola; já para descrever a raiz, flores e frutos recomenda-se o uso de gravuras. Para a compreensão do que sejam o cálice e a corola das flores, devem ser lembrados objetos designados por palavras semelhantes, coroa, por exemplo.

Essas lições são também ocasião para explicar a formação de palavras e há orientações para a distribuição desse conteúdo nas séries da escola primária: as lições sobre sementes e vegetais, nutrição e reprodução das plantas podem ser dadas para classes de $2^{\circ}$ e $3^{a}$ ano, porque os alunos já estariam familiarizados com a leitura e com o hábito da observação a ser exercitada com espécies cultivadas na sala de aula; para o $4^{\circ}$ ano, pode-se fazer uso de compêndios e, se a escola não dispuser de museu escolar, devem ser providenciados quadros e estampas.

Nos modelos de lições, entretanto, pode-se perceber que são exíguos o tempo e as oportunidades determinadas para a observação direta de objetos e coisas. Os exemplos de diálogos ou dos passos para a condução das aulas são suprimidos e se avolumam sínteses da matéria a ser ensinada que se assemelham a exposições típicas dos compêndios ${ }^{10}$, passando as prescrições metodológicas a segundo plano, conforme pode ser observado no trecho abaixo.

${ }^{10}$ Os compêndios, segundo Magalhães (2011), são livros escolares que se caracterizam pela adaptação do conteúdo dos tratados científicos. 
Recapitule-se até conseguir-se esse resultado:

Caule é a parte da planta que quase sempre se dirige de baixo para cima, e que sustenta as folhas e flores.

As plantas que têm o caule tão pequeno que não aparece, chamam-se plantas acaules.

O caule pode ser simples ou ramificado.

Caule simples é o que não tem galhos.

Caule ramificado é o que divide em galhos, ramos.

Os caules moles como os do milho, do arroz, chamam-se caules herbáceos.

Os caules duros como do bambu, do pinheiro, chamam-se lenhosos.

Os caules herbáceos ou lenhosos que têm de distância a distância nós de onde saem folhas, chamam-se colmos (PEREIRA, 1895, p. 282, grifos no original).

Mesmo nas lições referentes ao ensino da Leitura, primeiro conteúdo prescrito no livro e também assinado por A. Pereira, pode ser verificada a ausência de exercícios de observação. Citando Pestalozzi, o autor indica o uso da conversação, exemplificada com um detalhado diálogo entre professores e alunos. O diálogo apresentado como modelo é semelhante àqueles presentes no livro de Calkins, com a diferença não desprezível de que A. Pereira, prescindia da apresentação do objeto, rememorava observações pré-existentes, lançando mão de gravuras ou de palavras escritas na lousa. Assim, verifica-se que, independente do conteúdo abordado, há forte presença do ensino da linguagem e da formação de palavras nos modos de uso do método em sua versão paulista.

Ainda no campo das Ciências Naturais, as lições de Física são escritas por J. de Sant'Anna e nelas a adesão ao método de ensino intuitivo também é explícita. Há orientações para a observação de objetos existentes na sala de aula ou trazidos pelas crianças (madeira, esponja, moringa, etc.) sobre os quais poderão ser encetados os diálogos necessários à aprendizagem. Esclarece o autor que se a aula fosse destinada a adultos, muitos outros conhecimentos seriam transmitidos, mas em se tratando de crianças, deve ser seguido o preceito de Pestalozzi: "A medida dos conhecimentos não está no que se pode ensinar, mas no que as crianças podem aprender” (SANT'ANNA, 1895, p. 79).

Justifica ainda que a inclusão das Ciências Naturais no programa oficial de ensino o levaram a articular as noções sobre a matéria com o modo de ensina-las, isto é, conteúdo e método. Apesar dessas intenções, os conceitos se sobrepõem às indicações metodológicas, como pode ser conferido no excerto retirado de uma lição para o ensino da impenetrabilidade dos corpos:

Depois mandará um menino ficar em seu lugar. O menino naturalmente dirá: Não posso porque o senhor está aí.

Pergunte-se agora a toda classe: - Se esta sala estivesse completamente cheia de meninos poderia caber mais um?

A classe sem dúvida responderá: - Não, só se saísse um menino.

Depois que os meninos estiverem assim com o espírito bem formado, digase: 'Dois corpos não podem ocupar o mesmo lugar.' Com efeito para que uma garrafa encha-se de água é preciso que saia o ar; o prego não penetra na madeira, apenas afasta as fibras e por isso ele entra; a tinta não penetra no mata-borrão, ocupa apenas o espaço que constitui os poros.

E, assim as crianças ficarão bem de posse da ideia da impenetrabilidade, uma das propriedades dos corpos (SANT'ANNA, 1895, p. 76-77). 
Mesmo nas lições sobre temas mais propícios à observação pode-se verificar a mesma sobreposição, conforme ilustram as orientações para o ensino da gravidade:

Jogando-se uma pedra, um lápis, uma caneta, um pedaço de papel observa-se que todos estes corpos caem.

Podemos pois dizer às crianças que todos os corpos, em qualquer lugar, uma vez livres e abandonados, caem sempre para a terra na direção de uma linha vertical.

Joguem-se agora corpos de diferentes pesos e ver-se-á que os mais pesados caem mais depressa que os mais leves.

Conte-se às crianças que isto é devido à resistência do ar. De modo que se num lugar não houver ar todos os corpos caem igualmente com a mesma velocidade (SANT'ANNA, 1895, p. 80).

A adesão à inovação metodológica, bem como a intenção de vê-la disseminada, é inequívoca no discurso dos autores paulistas e, J. Sant'Anna entre eles, recomenda que o professor faça uso de muitos exemplos e de pequenas experiências para que as ideias adquiridas pelos alunos sejam claras. Com esse procedimento, segundo ele, seria possível evitar certos comportamentos que persistem até o ensino secundário, nos quais prevalecem as preleções que confundem "matéria explicada com matéria exposta" (SANT'ANNA, 1895, p. 83). A recapitulação frequente das lições e as perguntas aos alunos, segundo ele, podem evitar esses males.

A falta dos materiais necessários, no entanto, pode ser um vetor a modular o uso do método e o professor reconhece que "O meio mais fácil e metódico de ensinar tanto a física como a química, é mesmo fazendo experiências para os alunos verem. Mas, por enquanto, não dispomos de nenhum material para isso" (SANT'ANNA, 1895, p. 184). Essa dificuldade é mais acentuada nas lições para o ensino de Química, que versam sobre corpos simples, compostos e misturas exemplificados nos metais, pólvora, enxofre e carbono.

No entanto, na lição sobre a água, que é material de fácil acesso, não há sugestão para seu uso didático, mas sim explicações sobre sua composição, seus estados físicos e seus usos, nos seguintes termos:

A água compõe-se de dois gases hidrogênio e oxigênio, e é um corpo abundantíssimo na natureza. Também existe naturalmente debaixo de outros estados. Com efeito, no estado líquido encontramo-la formando os rios, lagos, mares; no estado gasoso, formando nuvens e finalmente no estado sólido, formando gelo nos polos e nos cumes das altas montanhas (SANT'ANNA, 1895, p. 186).

$\mathrm{Na}$ etapa final do estudo desse elemento aborda-se as condições de potabilidade da água e, para exemplificar, "o professor adiante da classe deve tomar um copo de água e mostrar a todos" (SANT'ANNA, 1895, p. 188). A síntese da lição, por meio da qual pretende-se verificar o que foi aprendido, não se distingue do conteúdo presente em compêndios cujo formato, por definição, prescinde de prescrições para a prática docente, justamente a dimensão que o livro A Eschola Publica pretendia disseminar entre o professorado. A síntese da lição, conforme pode ser observado no trecho abaixo, se atém à verificação de conceitos e noções e não à produção de um texto pelos alunos:

Pergunte-se que espécie de corpo é a água, onde se encontra, para que serve, onde se encontra a água nos estados sólidos, líquido e gasoso. Conte-se que a água própria para o uso doméstico chama-se potável e a que é imprópria, - impotável; que a água do mar, de alguns lagos é 
salgada e que a água do rio, das fontes, de alguns lagos, é doce. Contese também que a água é encontrada no sangue dos animais, na seiva dos vegetais, nos poços, etc." (SANT'ANNA, 1895, p. 188).

O verbo observar, central à concepção pestalozziana e à interpretação de Calkins, é substituído por outros nas prescrições didáticas de J. Sant'Anna: "Contai ainda às crianças que no vácuo ou vazio não há som. Explicai bem o que quer dizer vácuo ou vazio"; "Contai então a eles que o som caminha também num outro meio qualquer diferente do ar"; "Falai-lhes também na velocidade do som. Assim, contai que a velocidade do som é de $340 \mathrm{~m}$. por segundo" (SANT'ANNA, 1895, p. 92-933, grifos nosso). Contar, falar e explicar conformam, portanto, a interpretação do método apresentada no manual paulista.

\section{Considerações finais}

As fontes analisadas, bem como os excertos destacados, procuraram evidenciar os diferentes sentidos atribuídos ao método de ensino intuitivo nas décadas finais do século XIX. Vinculadas aos mesmos princípios educacionais, respaldadas pela experiência profissional de seus autores e legitimadas institucionalmente, essas interpretações destinavam-se a alterar as práticas docentes, daí a adoção de modelos de aula nas quais a intenção de inovar era objetivada.

Essas prescrições compuseram uma rede, integrada também pela legislação educacional, pelos impressos pedagógicos e por diversos agentes que desempenharam função estratégica para marcar realizações políticas e profissionais com o símbolo da mudança. Sob essa identidade de propósitos coexistiam diferentes prescrições para realiza-los, descritas na presente análise. Parte das diferenças entre os dois impressos estão relacionadas à modalidade editorial de cada uma delas: o manual, forma adotada por Calkins, favorece a exposição articulada dos fundamentos reguladores do método, dos procedimentos didáticos e dos modelos de lições; o manual paulista é compilação de artigos destinados, primordialmente, à exposição de modelos de aulas, ficando subentendidas as teorias das quais derivavam esses modelos.

$\mathrm{Na}$ versão paulista analisada, a inovação metodológica foi subordinada, principalmente, aos programas das disciplinas que, por serem bastante detalhados e abrangentes, determinavam o ritmo do método: menor sequência de passos para sua aplicação e maior volume de conceitos expostos. Inicialmente publicado em edições mensais e produzido por mais de um autor, esse manual tinha suas possibilidades inovadoras delimitadas por um currículo enciclopédico também veiculado no manual, justificando assim um discurso que incorporava tanto as informações compendiadas, pré-existentes, quanto as indicações metodológicas, a novidade a ser introduzida.

Os passos constitutivos do método de ensino, explicitados em cada uma das publicações, apresentam diferenças significativas em relação aos procedimentos que caracterizam o início e a conclusão das lições. A educação dos sentidos, priorizada na versão norte-americana é etapa rapidamente cumprida na versão paulista, funcionando como um pressuposto, e as definições, não necessariamente provenientes dos sentidos, privilegiam a linguagem; a conclusão do processo por meio de uma síntese baseada em quadro de palavraschave proposta por Calkins, é substituída no manual A Eschola Publica por uma lição já pronta que, no limite, pode prescindir das observações.

Essas diferenças explicitam, por sua vez, diferentes concepções sobre a ciência e sobre seu ensino uma vez que estão assentadas em diferentes formas de raciocínio e dos hábitos mentais que procuram gerar. O ritmo aplicado à observação, procedimento desencadeador do método intuitivo, e à síntese final, verificação do que foi aprendido conforme prescrito nos dois impressos, revelam que, na versão paulista, a articulação com a concepção de ciência ativa e transformadora, característica da Modernidade, que tem na visão seu aporte inicial e procura tornar o mundo físico e seus fenômenos inteligíveis ao homem é mais fraca do que na versão norte-americana. Os 
elementos a serem diretamente experimentados na versão paulista - as continuidades práticas permanecem assentados na memorização e no compêndio como depositários do saber, apesar de mescladas com inovações parciais dos procedimentos de ensino.

\section{Referências}

A ESCHOLA PUBLICA. Linguagem em lições de coisas I. São Paulo, v. 1, n. 6, p. 45-46, jan., 1894.

A ESCHOLA PUBLICA. Linguagem em lições de coisas II. São Paulo, v. 1, n. 7, p. 54-55, fev., 1894.

BARBOSA, Rui. Reforma do ensino primário e várias instituições complementares da instrução pública. Rio de Janeiro: Ministério da Educação e Saúde, 1947. (Obras completas, v. 10, t. 1-4).

BASTOS, Maria Helena Câmara. Pro Patria laboremus: Joaquim José de Menezes Vieira (1848-1897). Bragança Paulista: EDUSF, 2002.

BRASIL. Decreto-Lei no 7247, de 19 de abril de 1879. Reforma do ensino primário, secundário e superior no município da Corte em todo o Império. In: BARBOSA, R. Reforma do ensino secundário e superior. Rio de Janeiro: Ministério da Educação e Saúde, 1942, p. 273-303.

CALKINS, Nornam Allison. Primeiras lições de coisas: manual de ensino elementar para uso dos pais e professores. Tradução de Rui Barbosa. Obras Completas, v. XIII, tomo 1. Rio de Janeiro: Ministério da Educação e Saúde, [1886], 1950.

CARVAlHO, Marta Maria Chagas de. Modernidade pedagógica e Modelos de Formação Docente. São Paulo em Perspectiva, v.14, n.1, p.111-120, jan./mar., 2000. https://doi.org/10.1590/S0102-88392000000100013

CARVALHO, Marta Maria Chagas de. A caixa de utensílios e a biblioteca: pedagogia e práticas de leitura. In: VIDAL, D. G.; HILSDORF, M. L. (Orgs.). Brasil 500 anos: tópicas em história da educação. São Paulo: EDUSP, 2001. p. 137-167.

CARVAlHO, Marta Maria Chagas de. A escola e a República e outros ensaios. Bragança Paulista: EDUSF, 2003.

CATANI, Denice Barbara. Educadores à meia-luz: Um estudo sobre A Revista de Ensino da Associação Beneficente do professorado público de São Paulo (1902-1918). Bragança Paulista: EDUSF, 2003.

CHAMON, Carla Simone. Maria Guilhermina Loureiro de Andrade: a trajetória profissional de uma educadora (1864 1914). 2005. Tese (Doutorado em Educação) - Faculdade de Educação, Universidade Federal de Minas Gerais, Belo Horizonte, 2005.

GONÇALVES, Gisele Nogueira; WARDE, Mirian Jorge. Oscar Thompson. In: FÁVERO, M. L. De A.; BRITO, J. M. Dicionário de educadores no Brasil da Colônia aos dias atuais. Rio de Janeiro: Editora UFRJ/MEC-INEP, 2002. p. 867-872. 
HILSDORF, Maria Lucia. Francisco Rangel Pestana: jornalista, político, educador. 1986. Tese (Doutorado em Educação) - Faculdade de Educação, Universidade de São Paulo, São Paulo, 1986.

KIDDLE, Henry; HARRISON, Thomas e CALKINS, Norman Allison. How to teach. A graded Course of Instruction and Manual of Methods for the use of Teachers. New York: Van Antwerp, Bragg and Co., 1873.

MAGAlHÃES, Justino. O mural do tempo. Manuais escolares em Portugal. Lisboa: Edições Colibri/ Instituto de Educação da Universidade de Lisboa, 2011.

MONARCHA, Carlos. Escola Normal da Praça: o lado noturno das luzes. Campinas, SP: Editora da Unicamp, 1999.

MORTATTI, Maria do Rosário Longo. Os sentidos da alfabetização: São Paulo (1876 1994). São Paulo: Editora Unesp, 2000. https://doi.org/10.7476/9788539302697

MOTTA, Cesário. Nossa folha. In: THOMPSON, O. et al. A Eschola Publica: ensaio de Pedagogia Prática. São Paulo: Typographia Paulista, 1895, p. 8.

OLIVEIRA, Marcus Aldenison. Circulação. In: VALENTE, W. R. (Org.). Cadernos de Trabalho II. (volume 1). São Paulo: Editora Livraria da Física. 2018, p. 11-83

PEREIRA, Antonio R. A Zoologia em lições de coisas. In: THOMPSON, O. et al. A Eschola Publica: ensaio de Pedagogia Prática. São Paulo: Typographia Paulista, 1895, p. 95-138.

PEREIRA, Antonio R. Algumas lições de Botânica. In: THOMPSON, O. et al. A Eschola Publica: ensaio de Pedagogia Prática. São Paulo: Typographia Paulista, 1895, p. 273-305.

PINTO, Adriana Aparecida. Orientações pedagógicas e prescrições metodológicas: A Revista A Eschola Publica e a instrução (1893-1897). In: FURTADO, A. C.; BERTOLETTI, E. N. M.;

MOREIRA, K. H. (orgs.). História da Educação Escolar: múltiplas fontes, múltiplos olhares. São Carlos: Pedro \& João Editores, 2012. p. 153-173.

REIS FILHO, Casemiro. A educação e a ilusão liberal. 1. ed. São Paulo: Cortez/Autores Associados, 1981.

RIO DE JANEIRO. Primeira Exposição Pedagógica do Rio de Janeiro. Rio de Janeiro: Typographia Nacional, 1884.

SANT'ANNA, Joaquim. Physica I. In: THOMPSON, O. et al. A Eschola Publica: ensaio de Pedagogia Prática. São Paulo: Typographia Paulista, 1895, p. 73-94.

SANT'ANNA, Joaquim. Chimica. In: THOMPSON, O. et al. A Eschola Publica: ensaio de Pedagogia Prática. São Paulo: Typographia Paulista, 1895, p. 183-191.

SCHELBAUER, Analete Regina. Ideias que não se realizam. O debate sobre a educação do povo no Brasil de 1870 a 1914. Maringá: EDUEM, 1998. 
SILVEIRA, Carlos da. Apontamentos para uma história do ensino público em São Paulo: revistas de ensino. Educação. São Paulo, v. 7, n. 3, jun., 1929, p. 323-332.

SOBE, Noah. W. Entanglement and transnationalism in the History of American Education. In: POPKEWITZ, T. S. (ed.). Rethinking the History of Education. Transnational perspectives on its questions methods and knowledge. New York: Palgrave MacMillan, 2013, p. 93-107. https://doi.org/10.1057/9781137000705_5

SOUZA, Rosa Fatima. Templos de civilização: a implantação da escola primária graduada no Estado de São Paulo (1890-1910). São Paulo: Ed. da Unesp, 1998.

THOMPSON, Oscar et al. A Eschola Publica: ensaio de Pedagogia Prática. São Paulo: Typographia Paulista, 1895.

VALDEMARIN, Vera Teresa. Estudando as lições de coisas: análise dos fundamentos filosóficos do método do ensino intuitivo. Campinas: Autores Associados, 2004.

VALDEMARIN, Vera Teresa. O método intuitivo: os sentidos como janelas e portas que se abrem para um mundo interpretado. In: SAVIANI, D.; ALMEIDA, J. S.; SOUZA, R. F.; VALDEMARIN, V. T. (Orgs.). O legado educacional do século XIX. Campinas: Autores Associados, 2006.

VALDEMARIN, V. T; PINTO, A. A. Das formas de ensinar e conhecer o mundo: lições de coisas e método de ensino intuitivo na imprensa periódica educacional do século XIX. Revista Educação em questão. Natal/RN, v. 39, n. 25, p. 163-187, set./dez., 2010.

WARDE, Mirian Jorge. Oscar Thompson na Exposição de St. Louis (1904): an exhibit showing. In: FREITAS, M. C.; KUHLMANN JUNIOR, M. (Orgs.). Os Intelectuais na História da Infância. São Paulo: Cortez, 2002, p. 409-458.

WILliAMS, Raymond. Marxismo e Literatura. Tradução de Waltensir Dutra. Rio de Janeiro: Zahar, 1979. 